\title{
Gene Expression Profiles of Peripheral and Cord Blood Mononuclear Cells Altered by Thymic Stromal Lymphopoietin
}

\author{
MITSUYOSHI URASHIMA, MIO SAKUMA, SATOSHI TERAMOTO, YUICHI FUYAMA, \\ YOSHIKATSU ETO, KAZUHIRO KONDO, AND TADAO TANAKA \\ Division of Clinical Research and Development [M.U., M.S.], Jikei University School of Medicine, Tokyo \\ 105-8461, Japan; Department of Pediatrics [M.U., M.S., M.S., S.T., Y.F., Y.E.], Jikei University School of \\ Medicine, Tokyo 105-8461, Japan; Department of Obstetrics and Gynecology [T.T.], Jikei University \\ School of Medicine, Tokyo 105-8461, Japan; Department of Microbiology [K.K.], Institute of DNA \\ Medicine [Y.E.], Jikei University School of Medicine, Tokyo 105-8461, Japan
}

\section{ABSTRACT}

\begin{abstract}
Thymic stromal lymphopoietin (TSLP) was reported to induce dendritic cells to produce Th2-attracting chemokines, followed by allergic inflammation through stimulating not only CD4-positive T cells but also CD8-positive T cells. Therefore, in this experiment, GeneChip and hierarchical clustering were applied to screen the molecules in whole immunity triggered by TSLP directly and indirectly using both adult peripheral and cord blood mononuclear cells as well as isolated monocytes. Gene expression profiles screened a variety of molecules that are triggered by TSLP with or without CD40 ligation. In the profile, RNA expressions of indoleamine 2,3-dioxygenase, that is known to induce anergy of $\mathrm{T}$ cells and natural killer cells in protecting fetal rejection; many kinds of proteasomes that were reported to trigger cytokine production by inhibiting suppressors of NF- $\kappa \mathrm{B}$; and several kinds of chemokines increased, whereas RNA expression of superoxide dismutase 1 decreased, which was unexpected but considered worthy of notice. Expression of chemokines at protein levels and enzymatic activity of indoleamine 2,3-dioxygenase was further confirmed to increase in the pres-
\end{abstract}

ence of TSLP using ELISA and HPLC, respectively. These results suggest that the advent of microarray technology may enable us to screen novel molecular targets to treat TSLP-related allergic inflammation. (Pediatr Res 57: 563-569, 2005)

$\quad$ Abbreviations
CBMC, cord blood mononuclear cell
DC, dendritic cell
IDO, indoleamine 2,3-dioxygenase
IFN- $\gamma$, interferon- $\gamma$
MCP1, monocyte chemotactic protein-1
M-CSF, macrophage-colony stimulating factor
MDC, macrophage-derived chemokine
PBMC, peripheral blood mononuclear cell
TARC, thymus and activation-regulated chemokine
Th1, T helper 1
Th2, T helper 2
TNF- $\alpha$, tumor necrosis factor- $\alpha$
TSLP, thymic stromal lymphopoietin

Aberrant skewing to either T helper type 1 (Th1) or T helper type 2 (Th2) cells may cause autoimmune or allergic inflammatory disorders. The allergic diseases, including atopic eczema, food allergy, bronchial asthma, and allergic rhinoconjunctivitis, are considered the clinical results of inflammation triggered by dysregulated production of Th2-derived cytokines (1). Indeed, development of allergic inflammation in mice was prevented by administration of certain mycobacterial strains

Received May 24, 2004; accepted September 7, 2004.

Correspondence: Mitsuyoshi Urashima, M.P.H., M.D., Ph.D., Division of Clinical Research and Development, Jikei University School of Medicine, 3-25-8 Nishi-shimbashi,

Minato-ku, Tokyo 105-8461, Japan; e-mail: urashima@jikei.ac.jp.

Supported by Grant in Aid for Scientific Research (Japan).

DOI: 10.1203/01.PDR.0000155759.29448.13 through a shift from Th2 to Th1 immune responses (2). In addition to allergic inflammatory disorders, cord and neonatal blood are known to demonstrate Th2 dominant immunity (3), which is not a pathologic but rather a physiologic condition and explains the reduced reactivity of the maternal immune system against the fetal allograft (4). Despite Th2 skewing, neonates rarely have allergic reactions, and there is a low frequency of graft-versus-host disease in cord blood transplantation (5). Thus, cord blood may have different immunologic characteristics from adult blood, although these differences are not fully delineated.

Thymic stromal lymphopoietin (TSLP) has been cloned initially as a novel cytokine to promote B cell development in mice $(6,7)$. Recently, TSLP was found to mediate allergic 
inflammation by inducing dendritic cells (DCs) to produce the Th2-attracting chemokines thymus and activation-regulated chemokine (TARC; also known as CCL17) and macrophagederived chemokine (MDC; CCL22) in human (8). Furthermore, TSLP-primed DCs triggered naïve $\mathrm{CD}^{+} \mathrm{T}$ cells to produce IL-4, IL-5, IL-13, and tumor necrosis factor- $\alpha$ (TNF$\alpha$ ), while concurrently diminishing production of IL-10 and interferon- $\gamma(\mathrm{IFN}-\gamma)(8)$. In contrast to $\mathrm{CD}^{+}{ }^{+} \mathrm{T}$ cells, TSLPprimed DCs were demonstrated to trigger $\mathrm{CD} 8^{+} \mathrm{T}$ cells to secrete IL-5 and IL-13 and to induce cytolytic activity in concordance with CD40 ligation (9). Thus, TSLP affects not only DCs but also the immune system as a whole by inducing allergic inflammation by skewing to Th2 in human. However, whole pictures of Th2 skewing triggered by TSLP have not been elucidated.

The development of microarray methods for large-scale analysis of gene expression makes it possible to search systematically for key molecules (10). This search has been undertaken to differentiate gene expression profiles of Th1 cells from those of Th2 T cells (11-14) as well as to determine a molecular classification of cancer to predict a more precise prognosis (15). In this experiment, GeneChip and hierarchical clustering were applied to screen the molecules triggered by TSLP directly and indirectly by whole immunity using both peripheral blood mononuclear cells (PBMCs) and cord blood mononuclear cells (CBMCs). Gene expression profiles screened a variety of molecules triggered by TSLP with or without CD40 ligation. In the profile, RNA expressions of indoleamine 2,3-dioxygenase (IDO) that is known to induce anergy of $\mathrm{T}$ cells and natural killer cells in protecting fetal rejection; many kinds of proteasomes that were reported to trigger cytokine production by inhibiting suppressors of NF$\kappa \mathrm{B}$; and several kinds of chemokines increased, whereas RNA expression of superoxide dismutase 1 decreased, which was unexpected but considered worthy of notice. Expression of chemokines at protein levels and enzymatic activity of IDO was further confirmed to increase in the presence of TSLP.

\section{METHODS}

Preparation of blood-derived mononuclear cells. The Ethics Committee for Biomedical Research of the Jikei Institutional Review Board, Jikei University School of Medicine, approved the study protocol. All human subjects in this study provided written informed consent. Heparinized peripheral blood $(200 \mathrm{~mL})$ was obtained from 25 healthy adult male volunteers, and heparinized cord blood (50-100 mL) was obtained from eight placentas after normal delivery. Mononuclear cells were isolated by centrifugation on a Ficoll-Paque density gradient (Amersham Biosciences, Uppsala, Sweden). They were cultured for $96 \mathrm{~h}$ in $90 \%$ RPMI 1640 with L-glutamine/streptomycin-penicillin mixed medium supplemented with $10 \%$ fetal bovine serum at $37^{\circ} \mathrm{C}$ in a humidified $5 \% \mathrm{CO}_{2}$ atmosphere at $0.5 \times 10^{6} / \mathrm{mL}$ in $10 \mathrm{~mL}$ in the medium alone, with TSLP (20 ng/mL; R\&D Systems, Minneapolis, MN), with murine anti-CD40 MAb (1.0 $\mu \mathrm{g} / \mathrm{mL}$; R\&D Systems), or with both TSLP $(20 \mathrm{ng} / \mathrm{mL})$ and murine anti-CD40 MAb $(1.0 \mu \mathrm{g} / \mathrm{mL})$.

Isolation of monocytes from adult PBMCs and in vitro generation of macrophages. Isolation of human monocytes from peripheral blood was performed by depletion of nonmonocytes using the MACS monocytes isolation kit (Miltenyi Biotec, Auburn, CA). For depletion of T cells, natural killer (NK) cells, B cells, dendritic cells, and basophiles from PBMCs, these cells were indirectly magnetically labeled using a cocktail of hapten-conjugated CD3, CD7, CD19, CD45RA, CD56, and anti-IgE antibodies and MACS microbeads coupled to an anti-hapten MAb. The magnetically labeled cells were depleted by retaining them on a MACS column in the magnetic field of the MidiMACS. The final purity of monocytes was $>99 \%$ confirmed with anti-CD14 antibody.

The isolated monocytes from nine volunteers were cultured to differentiate macrophages for $7 \mathrm{~d}$ in the presence of macrophage-colony stimulating factor (M-CSF; $10 \mathrm{ng} / \mathrm{mL}$; R\&D Systems) with IFN- $\gamma$ (100 ng/mL) added for the final $18 \mathrm{~h}$ and used for GeneChip. For measurement of tryptophan and kynurenine concentrations, the in vitro-generated macrophages in the presence of M-CSF as well as PBMCs from the other eight volunteers were cultured for $96 \mathrm{~h}$ in at $0.5 \times 10^{6} / \mathrm{mL}$ in $1 \mathrm{~mL}$ in the medium alone, with IFN- $\gamma$ (100 ng/mL) or TSLP (20 ng/mL), with murine anti-CD40 MAb $(1.0 \mu \mathrm{g} / \mathrm{mL})$, or with both TSLP $(20 \mathrm{ng} / \mathrm{mL})$ and murine anti-CD40 MAb $(1.0 \mu \mathrm{g} / \mathrm{mL})$.

GeneChip expression analysis. Total RNA was isolated from cultured cells with RNeasy mini kits (Qiagen, Valencia, CA), according to the manufacturer's specifications. More than $11 \mu \mathrm{g}$ (median; range, $1.8-3.5 \mu \mathrm{g} / 10^{6}$ cells) was used for one GeneChip expression analysis. Human genome-wide gene expression was examined using the Human Genome Focus Array (GeneChip; Affymetrix, Santa Clara, CA), which contains the oligonucleotide probe set for $\sim 8500$ full-length genes, according to the manufacturer's protocol (Affymetrix). Double-stranded cDNA was synthesized, and the cDNA was subjected to in vitro transcription in the presence of biotinylated nucleotide triphosphates. The biotinylated cRNA was hybridized with a probe array for $16 \mathrm{~h}$ at $45^{\circ} \mathrm{C}$, and the hybridized biotinylated cRNA was stained with streptavidin-phycoerythrin and then scanned with a Gene Array Scanner. The fluorescence intensity of each probe was quantified using a computer program, GeneChip Analysis Suite 5.0 (Affymetrix). The expression level of a single RNA was determined as the average fluorescence intensity among the intensities obtained by 11 paired (perfect matched and single nucleotide mismatched) probes that consisted of 25-mer oligonucleotides. When the intensities of mismatched probes were very high, gene expression was judged to be absent even when a high average fluorescence was obtained with the GeneChip Analysis Suite 5.0 program. The level of gene expression was determined as the average difference using GeneChip software.

ELISA for chemokines. M-CSF-generated macrophage culture supernatants were collected at $96 \mathrm{~h}$, frozen at $-80^{\circ} \mathrm{C}$, and analyzed within 1 mo using ELISA kits for human TNF- $\alpha$, TARC, MDC, monocyte chemotactic protein-1 (MCP-1 or CCL2), and RANTES (CCL5; R\&D Systems).

HPLC determination of tryptophan and kynurenine. Total free tryptophan and kynurenine were quantified in culture media by HPLC as previously described (16). A 1-mL volume of medium was mixed with $0.2 \mathrm{~mL}$ of $30 \%$ trichloroacetic acid and centrifuged at $2000 \times g$ for $5 \mathrm{~min}$. The supernatant was filtered though a $0.45-\mu \mathrm{m}$-probe-size filter. The chromatography was performed in a Shimadzu LC-10A liquid chromatograph. The chromatographic separation was achieved using a column of Shim-pack CLC-ODS $(6.0 \mathrm{~mm}$ ID $\times 150 \mathrm{~mm} \mathrm{~L})$ and a guard column of Shim-pack of GVP-ODS (4) $(4.0 \mathrm{~mm} \mathrm{ID} \times 10 \mathrm{~mm} \mathrm{~L})$ at $40^{\circ} \mathrm{C}$ and flow rate of $1.0 \mathrm{~mL} / \mathrm{min}$ with $3 \% \mathrm{CH}_{3} \mathrm{CN} / 100 \mathrm{mM} \mathrm{NaH}_{2} \mathrm{PO}_{4}(\mathrm{pH} \mathrm{3.3})$. The absorbance of the column effluent was monitored at 285 and $365 \mathrm{~nm}$ for tryptophan and kynurenine, respectively.

Statistics. To eliminate changes within the range of background noise and to select the most differentially expressed genes, we used data only when raw data values were $<50$ average difference and the gene expression was judged to be present by Affymetrix data analysis. Next, we used an SD threshold of 50 average difference to select the most variably expressed sequences. Hierarchical clustering was analyzed with the Spotfire software version 7.0 (Spotfire, Somerville, MA) (17). The $z$ score is the SD from the normal mean value of raw data transformed by $\log 2$ in each gene and used as normalization. For gene names, http://dr-urashima.jp/excel/genenames.xls; for raw data of PBMCs: http://dr-urashima.jp/excel/PBMCs.xls; for raw data of CBMCs: http://dr-urashima.jp/excel/CBMCs.xls: for raw data of macrophages: http:// dr-urashima.jp/excel/macrophages.xls. Concentrations of chemokines and tryptophan/kynurenine in each condition were compared with medium alone using Wilcoxon signed-rank test.

\section{RESULTS}

Comparison of gene expression profiles between IFN- $\gamma$ stimulated macrophages, PBMCs, and CBMCs with or without TSLP and/or anti-CD40 antibody. First, we applied hierarchical clustering to classify all 82 samples, using the 1818 most variably expressed transcripts. The resulting clusters demonstrated distinctions between IFN- $\gamma$-stimulated macrophages, CBMCs, and PBMCs despite the absence or presence of TSLP and/or anti-CD40 antibody (Fig. 1).

Some specific genes in clusters were selected when they belonged to a group with similar functions. PBMCs expressed 


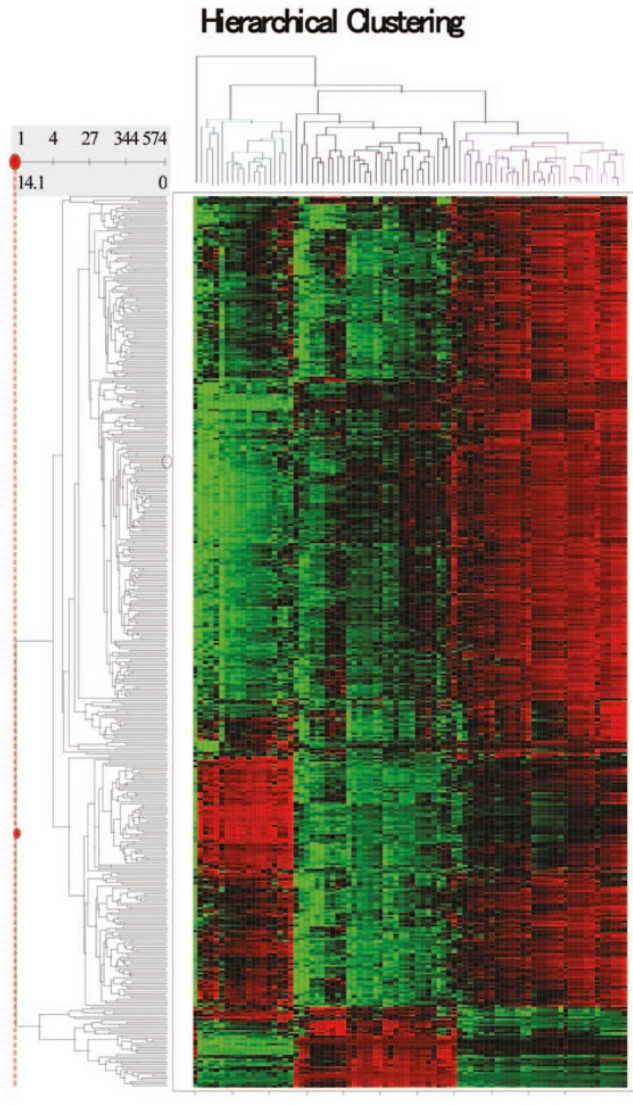

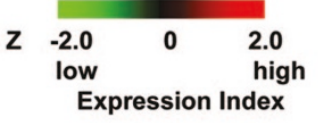

(A)

granzyme K

IL4R. IL13RA1, PSMB4

granzyme $\mathrm{A}, \mathrm{CD} 32, \mathrm{CD} 6, \mathrm{CD} 2$

CCL22, CCL5, CCR2, CX3CR1,

RPL14, RPL18, RPL23, RPL29, RPL35, RPL4, RPL5, RPL6, RPS10, RPS19, RPS5, RPS6. RPS6KA3, RPS7, RPS9, RPLP2, RPLP0

/CCL4, IL1B, CSF1,CSF2RB, MMP9,

ALCAM, CD44, Lamin, BCL3,

Kynureninase, kynurenine 3-monooxygenase

IL2RB, CD83, granzyme B, NKG7

IDO, ICAM, CD33, CD97, prostaglandin D2 synthase

TNF, CCL8, CXCL9, CXCL10, CXCL11, IL15RA, TLR8, PSME2, PSMB9, PSMB10

CCR5, C3, TLR7, CD4, CD74, IL10RA, TGFBR2

HLA-DMA, HLA-DMB, HLA-DQA1, HLA-DRA,

HLA-DRB1, HLA-DRB4, HLA-DRB5

PSMA5, PSMB8

CXCL4, CXCL7, CD16,

(B)

Hemoglobin A1, B, D, G1, G2, glycophorin B, C, myeloperoxidase

Synuclein, RNase A, apolipoprotein E,

Figure 1. Comparison of gene expression profiles between IFN- $\gamma$-stimulated monocytes, PBMCs, and CBMCs with or without TSLP and/or anti-CD40 antibody. Two-dimensional hierarchical clustering was applied to classify all 82 samples of IFN- $\gamma$-stimulated monocytes with or without anti-CD40 antibody $(n=18)$, PBMCs with or without TSLP and/or anti-CD40 antibody $(n=32)$, and CBMCs with or without TSLP and/or anti-CD40 antibody $(n=32)$, using the 1818 most variably expressed transcripts. The normalized expression index for each transcript sequence (rows) in each sample (columns) is indicated by a color code (see Expression Index bar at top right of figure). Computation clearly separated 82 samples into three clusters (columns); 18 samples of monocytes indicated with clustering bars in light blue, 32 samples with CBMCs indicated with clustering bars in black, 32 samples with PBMCs indicated with clustering bars in purple. (A) Clusters of genes (rows) with high relative expression in PBMCs (some genes are indicated by purple). (B) Clusters of genes with high relative expression in both monocytes and PBMCs (some genes are indicated with light blue). (C) Clusters of genes with high relative expression in CBMCs (some genes are indicated in black).

higher levels of granzymes (B, K, A), many kinds of proteasomes (RPL14, RPL18, RPL23, RPL29, RPL35, RPL4, RPL5, RPL6, RPS10, RPS19, RPS5, RPS6, RPS6KA3, RPS7, RPS9, RPLP2, RPLP0), some kinds of chemokines (CCL22, CCL5, CCR2, CX3CR1, CCL4), and receptors for IL-4 and IL-13 than monocytes and CBMCs. Macrophages and PBMCs both showed higher level expression of IDO as well as kynureninase and kynurenine 3-monooxygenase than CBMCs. In contrast, HLA-D-related antigens were lower, whereas RNA expressions of Hb-related genes, myeloperoxidase, synuclein, Rnase, and apolipoprotein E were higher in CBMCs than others.

Effects of TSLP and/or CD40 ligation on PBMCs. Next, hierarchical clustering was applied to determine the effect of TSLP and/or CD40 ligation focusing on PBMCs, using the 951 most variably expressed transcripts. Computation clearly separated 32 samples into four clusters: eight samples cultured in medium alone, eight samples with anti-CD40 antibody, eight samples with TSLP, and eight samples with both TSLP and anti-CD40 antibody (Fig. 2).

As mentioned previously (8), TARC and MDC were upregulated in the presence of TSLP with or without CD40 ligation. Moreover, IDO and kynureninase as well as TNF- $\alpha$ increased in the presence of TSLP. RNA expressions of these molecules were further enhanced by combination of TSLP and anti-CD40 antibody. Proteasomes were specifically increased in the presence of TSLP with or without anti-CD40 antibody. In contrast, superoxide dismutase was decreased by TSLP. Moreover, CD40 ligation decreased CCL5, CX3CR1, and CXCR4, whereas it increased CD19, CD83, and thymidine synthetase.

Effects of TSLP and/or CD40 ligation on CBMCs. As performed in PBMCs, hierarchical clustering was used to determine the effect of TSLP and/or CD40 ligation on CBMCs, using the 1375 most variably expressed transcripts (Fig. 3). Computation failed to separate 32 samples in association with culture conditions. However, proteasomes and kynureninase increased in the presence of TSLP.

Confirmation of increased expressions of cytokines/ chemokines at protein levels. Typical cytokines and chemokines were measured at protein levels to confirm validity of GeneChip expression analysis using macrophages (Fig. 4). TARC and MDC increased by TSLP or CD40L, which was 


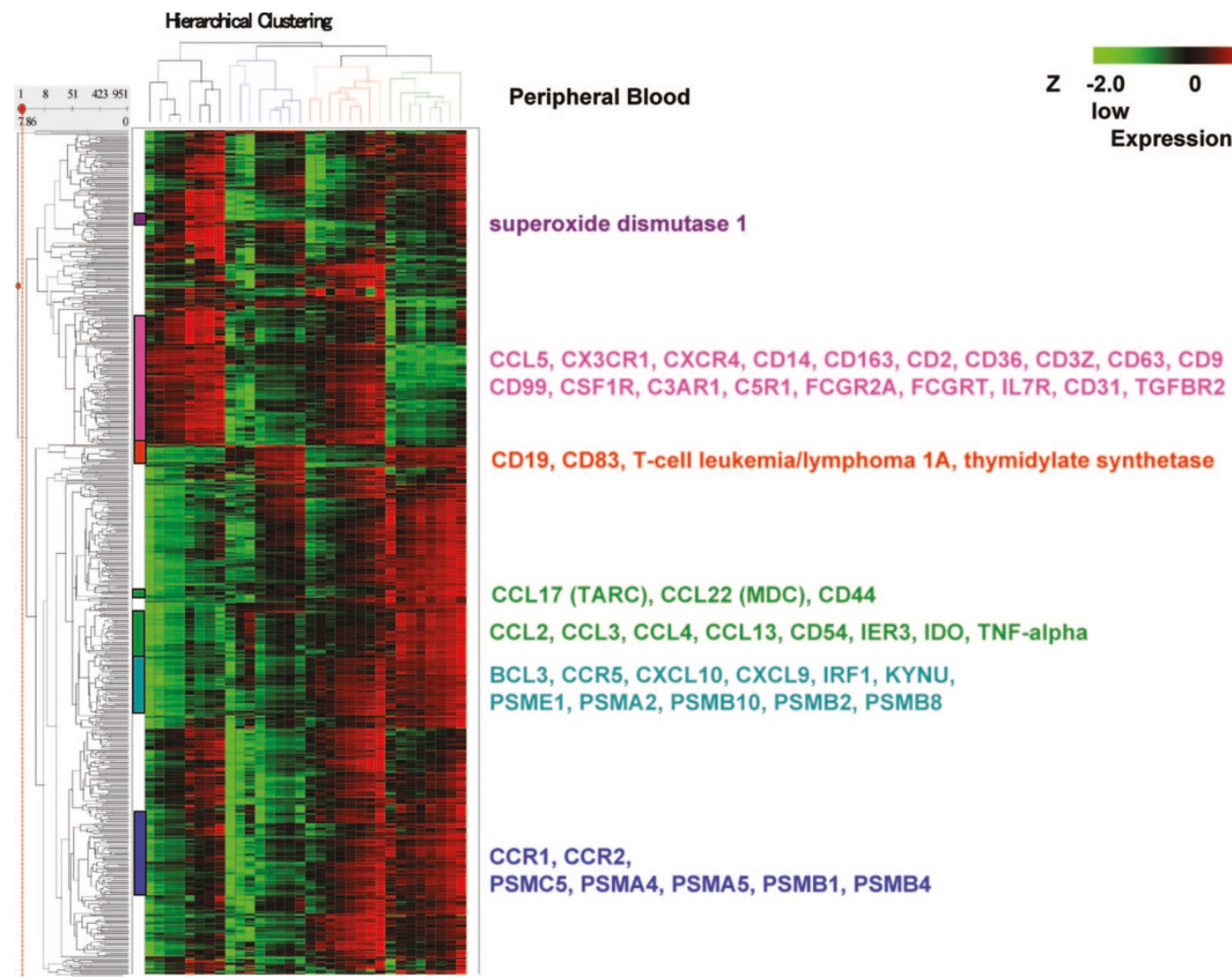

(A)

(B)

Figure 2. Gene expression clusters and PBMCs with or without TSLP and/or anti-CD40 antibody. Two-dimensional hierarchical clustering was applied to determine the effect of TSLP and/or CD40 ligation focusing on PBMCs, using the 951 most variably expressed transcripts. Computation clearly separated 32 samples into four clusters (columns): eight samples cultured in medium alone indicated with clustering bars in black, eight samples with anti-CD40 antibody indicated with clustering bars in blue, eight samples with TSLP indicated with clustering bars in red, and eight samples with both TSLP and anti-CD40 antibody indicated with clustering bars in green. (A) Clusters of genes (rows) with high relative expression in media (some genes are indicated by purple). (B) Clusters of genes with high relative expression both in media alone and with TSLP (some genes are indicated by pink). (C) Clusters of genes with high relative expression with anti-CD40 antibody with or without TSLP (some genes are indicated by red). (D) Clusters of genes with high relative expression in TSLP plus anti-CD40 antibody (some genes are indicated by green). (E) Clusters of genes with high relative expression in both TSLP alone and TSLP plus anti-CD40 antibody (some genes are indicated with light blue and blue).

further enhanced in the presence of both TSLP and CD40L. Similarly, MCP-1 and TNF- $\alpha$ were synergistically increased in the presence of both TSLP and CD40L. In contrast, protein levels of RANTES were decreased in the presence of TSLP.

Effects of TSLP and/or CD40 ligation on IDO activity in monocytes and in PBMCs. PBMCs (Fig. 5A) and macrophages $\left(0.5 \times 10^{6}\right.$ cells $\left./ \mathrm{mL}\right)$ that were generated from adult PBMCs in the presence of M-CSF (10 ng/mL; Fig. $5 B)$ were cultured for $96 \mathrm{~h}$ in medium alone with TSLP; anti-CD40 antibody; and a combination of TSLP, anti-CD40 antibody, and IFN- $\gamma$ (100 $\mathrm{ng} / \mathrm{mL}$ ). Then, concentrations of tryptophan and kynurenine were measured using HPLC.

Using PBMCs, concentrations of tryptophan decreased in the presence of IFN- $\gamma(p=0.014)$, TSLP $(p=0.013)$, and TSLP plus anti-CD40 antibody $(p=0.020)$; these decreases were significantly different from medium alone. However, concentration of tryptophan did not alter in the presence of anti-CD40 antibody. In contrast, concentrations of kynurenine decreased significantly only in the presence of IFN- $\gamma(p=0.015)$ but did not significantly change in other conditions. M-CSF-generated macrophages showed similar tendency observed in PBMCs.

\section{DISCUSSION}

Immune cascades from initial stimulation to inflammation are highly complex processes involving alterations in the expressions of a variety of genes. The advent of microarray technology has enabled us to screen not only expected but also unexpected alterations in gene expressions. In this study, gene expression profiles were applied to screen important molecules when blood mononuclear cells were stimulated with TSLP and/or anti-CD40 antibody as a whole. Because each type of immune cell, such as DCs and CD4/CD8-positive T cells, stimulates or suppresses each other; the effects of cytokines on specific immune cells may not represent whole immune reactions to the cytokines. Therefore, whole mononuclear cells were used to screen unexpected molecules from thousands of genes, as reported previously in antigenstimulated PBMCs, as used in a previous report (18).

Among a variety of gene expressions altered by the addition of TSLP, we targeted IDO, which is a rate-limiting enzyme, to catabolize tryptophan to kynurenine (19). RNA expression of IDO was up-regulated in the presence of TSLP, which was enhanced by CD40 ligation in this study. These altered expressions were 


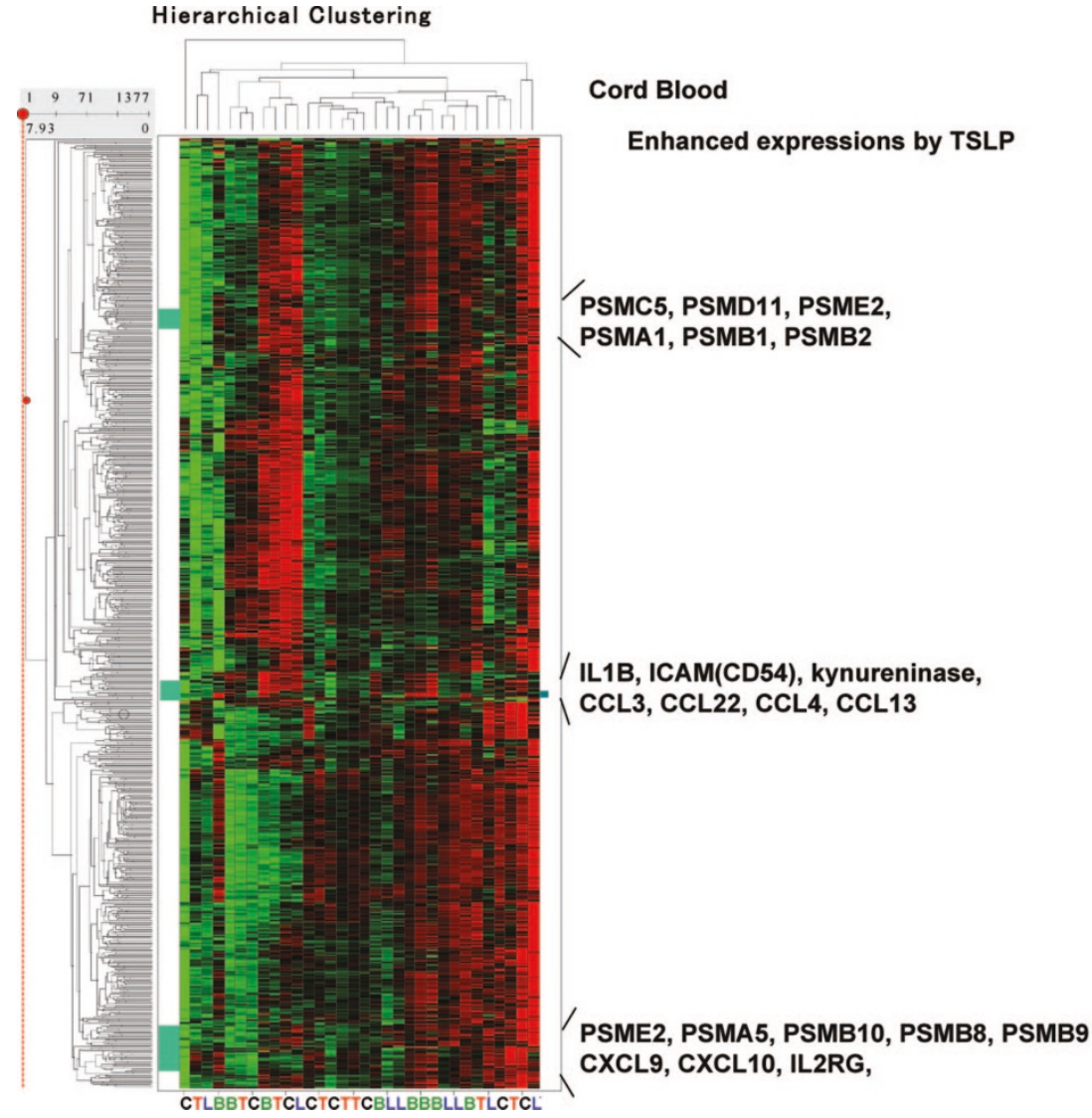

Figure 3. Effects of TSLP and/or CD40 ligation on CBMCs. Two-dimensional hierarchical clustering was applied to determine the effect of TSLP and/or CD40 ligation focusing on CBMCs, using the 1375 most variably expressed transcripts. Computation failed to separate 32 samples in association with culture conditions. However, proteasomes, some chemokines, and kynureninase increased in the presence of TSLP as indicated.

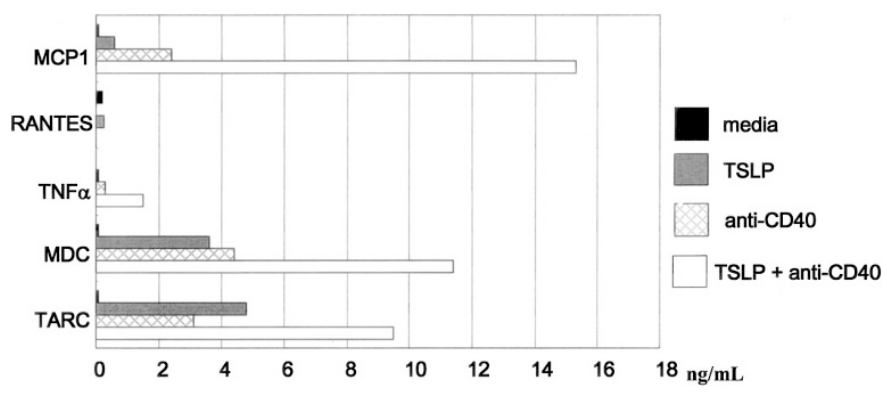

Figure 4. Confirmation of increased expressions of cytokines/chemokines at protein levels. MCP-1 (CCL2), RANTES (CCL5), TNF- $\alpha$, TARC (CCL17), and MDC (CCL22) in supernatants of monocytes derived from eight different donors in medium alone, monocytes cultured with anti-CD40 antibody, monocytes cultured with TSLP, and monocytes cultured with both TSLP and anti-CD40 antibody for $96 \mathrm{~h}$ using ELISA. *Statistical significance: $p<0.05$.

further examined to parallel the enzymatic function of IDO, as IDO protein can exist in both enzymatically active and inactive states $(20,21)$. In this study, the enzymatic activity was confirmed by a decrease in tryptophan in the culture supernatants that paralleled their RNA expression levels in PBMCs as well as in macrophages. Local tryptophan degradation by IDO was discovered to suppress T cell (21) and NK cell proliferation $(22,23)$, resulting in protecting against fetal rejection $(24,25)$ or escaping tumor rejection $(26,27)$. Thus, IDO works as an immune suppressor, generally. In contrast, TSLP transgenic mice developed to systemic inflammation including glomerulonephritis $(28,29)$.

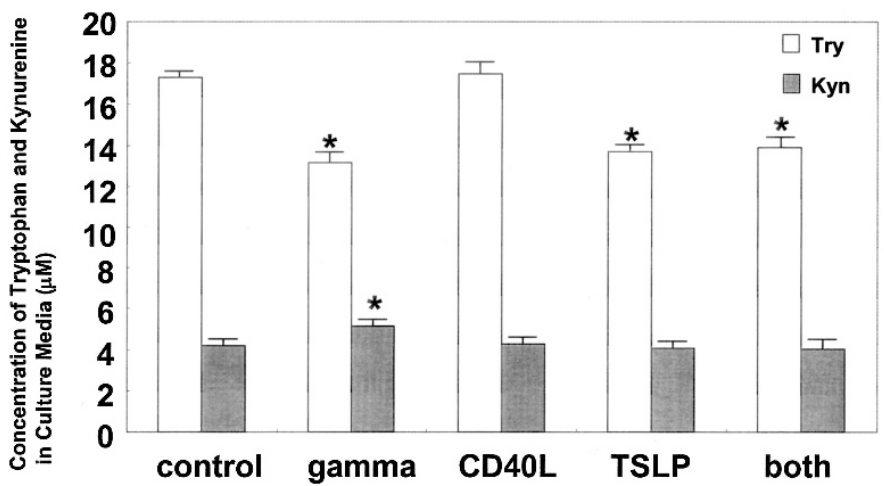

Figure 5. Changes of tryptophan and kynurenine concentrations in the presence of IFN- $\gamma$, TSLP, and/or anti-CD40 antibody. Tryptophan and kynurenine concentration in cultures of cells derived from different donors in medium alone, with anti-CD40 antibody, with TSLP, and monocytes with both TSLP and anti-CD40 antibody for $96 \mathrm{~h}$. Tryptophan and kynurenine concentrations were determined with HPLC. (A) PBMCs $(n=8)$ were used. $(B)$ Monocytes $(n=8)$ were used. *Statistical significance: $p<0.05$.

Similarly, CD40 ligation also stimulates immunity (30). Induction of IDO may play a role in suppressing inflammation triggered by TSLP with or without CD40 ligation. IFN- $\gamma$ that is also known as an immune stimulator was demonstrated to induce expression of IDO in our study and previous literature (31), suggesting the existence of similar mechanisms for negative regulation against overinflammation. 
In the comparison between CBMCs and PBMCs, HLArelated antigens were lower in CBMCs, which is consistent with a previous report indicating that hypoimmunoresponses of cord blood might be due to low cell surface expressions of HLA and cell adhesion molecules (32). Moreover, hematopoietic progenitor cells are circulating in CBMCs (33), resulting in higher expressions of RNA for $\mathrm{Hb}$ and myeloperoxidase than PBMCs observed in this study. In addition, higher expressions of synuclein known to associate with Parkinson's disease (34), RNase reported to relate with interference (35), and apolipoprotein E considered as Alzheimer's disease (36) were observed in CBMCs than in PBMCs, although the meanings of them expressed in CBMCs should be investigated as future directions. Furthermore, the proportions of blood cell components in CBMCs are different from PBMCs (37).

PBMCs expressed higher levels of granzymes, which may also explain decreased cytotoxic activity in cord blood (38). Of interest, many kinds of proteasomes were higher in PBMCs than in CBMCs; in addition, TSLP further increased the expressions of proteasomes in PBMCs. The transcription factor $\mathrm{NF}-\kappa \mathrm{B}$ is thought to have a central role in the induction of proinflammatory gene expression (39), the function of which is classically regulated by proteasomal degradation of its associated inhibitors $\mathrm{I} \kappa \mathrm{B} \alpha$ and $\mathrm{I} \kappa \mathrm{B} \beta(40)$. Thus, increased expressions of proteasomes may enhance the function of NF- $\kappa \mathrm{B}$, resulting in secretion of a variety of cytokines.

Chemokines, a superfamily of polypeptide mediators, play important roles in attracting immune cells (41-43), which were also different among PBMCs, CBMCs, and macrophages. PBMCs expressed CCL22 (MDC), a Th2 chemokine; CCL5 (RANTES), which is expressed on normal T cells; CCR2, which is essential for efficient collateral artery growth (44); and CX3CR1 (Fractalkine), a Th1-type chemokine that is expressed on NK cells and on monocytes (45). In contrast, expressions of CXCL4 (platelet factor 4) and CXCL7, which stimulates neutrophils to undergo firm adhesion to endothelial cells, transendothelial migration, and exocytosis of their secondary granule contents $(46,47)$, were higher in CBMCs than in other cells. Expressions of CCL5, CX3CR1, and CXCR4 were suppressed by CD40 ligation, whereas those of CCL17 (TARC) and CCL22 (MDC) were up-regulated in the presence of TSLP, as previously reported (8). In addition, CCL2 (MCP$1)$, which is involved in inflammatory disorders of the lung (48); CCL3, a macrophage inflammatory protein- $1 \alpha$; CCL4; CCL13; CCR5; CR1; CCR2; CXCL9; and CXCL10 (49) were up-regulated by TSLP.

In conclusion, the advent of microarray technology may enable us to screen novel molecular targets to treat TSLPrelated allergic inflammation, although further validation studies using functional assay should be needed for each screened molecule.

Acknowledgments. We appreciate Ms. Agawa for GeneChip scanning and Ms. Tomaru for analysis of tryptophan/ kynurenine measurement with HPLC in Institute of DNA Medicine, Jikei University School of Medicine.

\section{REFERENCES}

1. Busse WW, Lemanske RF Jr 2001 Asthma. N Engl J Med 344:350-362

2. Zuany-Amorim C, Sawicka E, Manlius C, Le Moine A, Brunet LR, Kemeny DM, Bowen G, Rook G, Walker C 2002 Suppression of airway eosinophilia by killed Mycobacterium vaccae-induced allergen-specific regulatory T-cells. Nat Med 8:625629

3. Forsthuber T, Yip HC, Lehmann PV 1996 Induction of TH1 and TH2 immunity in neonatal mice. Science 271:1728-1730

4. Behrman RE, Kliegman RM, Jenson HB 2003 Nelson Textbook of Pediatrics. Elsevier Science, Philadelphia, pp 743-747

5. Wagner JE, Rosenthal J, Sweetman R, Shu XO, Davies SM, Ramsay NK, McGlave PB, Sender L, Cairo MS 1996 Successful transplantation of HLA-matched and HLA-mismatched umbilical cord blood from unrelated donors: analysis of engraftment and acute graft-versus-host disease. Blood 88:795-802

6. Levin SD, Koelling RM, Friend SL, Isaksen DE, Ziegler SF, Perlmutter RM, Farr AG 1999 Thymic stromal lymphopoietin: a cytokine that promotes the development of $\mathrm{IgM}+\mathrm{B}$ cells in vitro and signals via a novel mechanism. J Immunol 162:677-683

7. Sims JE, Williams DE, Morrissey PJ, Garka K, Foxworthe D, Price V, Friend SL, Farr A, Bedell MA, Jenkins NA, Copeland NG, Grabstein K, Paxton RJ 2000 Molecular cloning and biological characterization of a novel murine lymphoid growth factor. J Exp Med 192:671-680

8. Soumelis V, Reche PA, Kanzler H, Yuan W, Edward G, Homey B, Gilliet M, Ho S, Antonenko S, Lauerma A, Smith K, Gorman D, Zurawski S, Abrams J, Menon S, McClanahan T, de Waal-Malefyt Rd, Bazan F, Kastelein RA, Liu YJ 2002 Human epithelial cells trigger dendritic cell mediated allergic inflammation by producing TSLP. Nat Immunol 3:673-680

9. Gilliet M, Soumelis V, Watanabe N, Hanabuchi S, Antonenko S, Waal-Malefyt Rd, Liu YJ 2003 Human dendritic cells activated by TSLP and CD40L induce proallergic cytotoxic T cells. J Exp Med 197:1059-1063

10. Schena M, Shalon D, Davis RW, Brown PO 1995 Quantitative monitoring of gene expression patterns with a complementary DNA microarray. Science 270:467-470

11. Chtanova T, Kemp RA, Sutherland AP, Ronchese F, Mackay CR 2001 Gene microarrays reveal extensive differential gene expression in both $\mathrm{CD} 4(+)$ and CD8(+) type 1 and type 2 T cells. J Immunol 167:3057-3063

12. Hamalainen H, Zhou H, Chou W, Hashizume H, Heller R, Lahesmaa R 2001 Distinct gene expression profiles of human type 1 and type $2 \mathrm{~T}$ helper cells. Genome Biol 2:RESEARCH0022

13. Hashimoto S, Nagai S, Sese J, Suzuki T, Obata A, Sato T, Toyoda N, Dong HY, Kurachi M, Nagahata T, Shizuno K, Morishita S, Matsushima K 2003 Gene expression profile in human leukocytes. Blood 101:3509-3513

14. Zelenika D, Adams E, Humm S, Graca L, Thompson S, Cobbold SP, Waldmann H 2002 Regulatory $\mathrm{T}$ cells overexpress a subset of Th2 gene transcripts. J Immunol 168:1069-1079

15. Ishibashi Y, Hanyu N, Nakada K, Suzuki Y, Yamamoto T, Yanaga K, Ohkawa K, Hashimoto N, Nakajima T, Saito H, Matsushima M, Urashima M 2003 Profiling gene expression ratios of paired cancerous and normal tissue predicts relapse of esophageal squamous cell carcinoma. Cancer Res 63:5159-5164

16. Widner B, Werner ER, Schennach H, Fuchs D 1999 An HPLC method to determine tryptophan and kynurenine in serum simultaneously. Adv Exp Med Biol 467:827832

17. Eisen MB, Spellman PT, Brown PO, Botstein D 1998 Cluster analysis and display of genome-wide expression patterns. Proc Natl Acad Sci USA 95:14863-14868

18. Mellor AL, Munn DH 1999 Tryptophan catabolism and T-cell tolerance: immunosuppression by starvation? Immunol Today 20:469-473

19. Munn DH, Sharma MD, Lee JR, Jhaver KG, Johnson TS, Keskin DB, Marshall B, Chandler P, Antonia SJ, Burgess R, Slingluff CL Jr, Mellor AL 2002 Potential regulatory function of human dendritic cells expressing indoleamine 2,3-dioxygenase. Science 297:1867-1870

20. Gong F, Yanofsky C 2001 Reproducing tna operon regulation in vitro in an S-30 system. Tryptophan induction inhibits cleavage of TnaC peptidyl-tRNA. J Biol Chem 276:1974-1983

21. Munn DH, Shafizadeh E, Attwood JT, Bondarev I, Pashine A, Mellor AL 1999 Inhibition of $\mathrm{T}$ cell proliferation by macrophage tryptophan catabolism. J Exp Med 189:1363-1372

22. Frumento G, Rotondo R, Tonetti M, Damonte G, Benatti U, Ferrara GB 2002 Tryptophan-derived catabolites are responsible for inhibition of $\mathrm{T}$ and natural killer cell proliferation induced by indoleamine 2,3-dioxygenase. J Exp Med 196:459-468

23. Terness P, Bauer TM, Rose L, Dufter C, Watzlik A, Simon H, Opelz G 2002 Inhibition of allogeneic $\mathrm{T}$ cell proliferation by indoleamine 2,3-dioxygenaseexpressing dendritic cells: mediation of suppression by tryptophan metabolites. J Exp Med 196:447-457

24. Munn DH, Zhou M, Attwood JT, Bondarev I, Conway SJ, Marshall B, Brown C, Mellor AL 1998 Prevention of allogeneic fetal rejection by tryptophan catabolism. Science 281:1191-1193

25. Mellor AL, Sivakumar J, Chandler P, Smith K, Molina H, Mao D, Munn DH 2001 Prevention of $\mathrm{T}$ cell-driven complement activation and inflammation by tryptophan catabolism during pregnancy. Nat Immunol 2:64-68

26. Friberg M, Jennings R, Alsarraj M, Dessureault S, Cantor A, Extermann M, Mellor AL, Munn DH, Antonia SJ 2002 Indoleamine 2,3-dioxygenase contributes to tumor cell evasion of T cell-mediated rejection. Int J Cancer 101:151-155

27. Uyttenhove C, Pilotte L, Theate I, Stroobant V, Colau D, Parmentier N, Boon T, Van Den Eynde BJ 2003 Evidence for a tumoral immune resistance mechanism based on tryptophan degradation by indoleamine 2,3-dioxygenase. Nat Med 9:1269-1274 
28. Osborn MJ, Ryan PL, Kirchhof N, Panoskaltsis-Mortari A, Mortari F, Tudor KS 2004 Overexpression of murine TSLP impairs lymphopoiesis and myelopoiesis. Blood 103:843-851

29. Muhlfeld AS, Segerer S, Hudkins K, Farr AG, Bao L, Kraus D, Holers VM, Quigg RJ, Alpers CE 2004 Overexpression of complement inhibitor Crry does not preven cryoglobulin-associated membranoproliferative glomerulonephritis. Kidney Int $65: 1214-1223$

30. Kuwashima N, Kageyama S, Eto Y, Urashima M 2001 CD40 ligand immunotherapy in cancer: an efficient approach. Leuk Lymphoma 42:1367-1377

31. MacKenzie CR, Hadding U, Daubener W 1998 Interferon-gamma-induced activation of indoleamine 2,3-dioxygenase in cord blood monocyte-derived macrophages inhibits the growth of group B streptococci. J Infect Dis 178:875-878

32. Hunt DW, Huppertz HI, Jiang HJ, Petty RE 1994 Studies of human cord blood dendritic cells: evidence for functional immaturity. Blood 184:4333-4343

33. Urashima M, Hoshi Y, Shishikura A, Kamijo M, Kato Y, Akatsuka J, Maekawa K 1994 Umbilical cord blood as a rich source of immature hematopoietic stem cells. Acta Paediatr Jpn 36:649-655

34. Schapira AH 2004 Disease modification in Parkinson's disease. Lancet Neurol 3:362-368

35. Agrawal N, Dasaradhi PV, Mohmmed A, Malhotra P, Bhatnagar RK, Mukherjee SK 2003 RNA interference: biology, mechanism, and applications. Microbiol Mol Biol Rev 67:657-685

36. Weller RO, Nicoll JA 2003 Cerebral amyloid angiopathy: pathogenesis and effects on the ageing and Alzheimer brain. Neurol Res 25:611-616

37. Urashima M, Hoshi Y, Akiyama M, Kamijo M, Shishikura A, Kato Y, Akatsuka J, Maekawa K 1995 Effects of cytokines on hematopoietic progenitor cells in cord blood, in bone marrow, and in peripheral blood mobilized by chemotherapy and G-CSF. Acta Paediatr Jpn 37:21-26

38. Gardiner CM, Meara AO, Reen DJ 1998 Differential cytotoxicity of cord blood and bone marrow-derived natural killer cells. Blood 91:207-213

39. Lawrence T, Gilroy DW, Colville-Nash PR, Willoughby DA 2001 Possible new role for NF- $\kappa \mathrm{B}$ in the resolution of inflammation. Nat Med 7:1291-1297
40. Shumway SD, Miyamoto S 2004 A mechanistic insight into a proteasomeindependent constitutive inhibitor $\kappa \mathrm{B} \alpha(\mathrm{I} \kappa \mathrm{B} \alpha)$ degradation and nuclear-factor $\kappa \mathrm{B}$ $(\mathrm{NF}-\kappa \mathrm{B})$ activation pathway in WEHI-231 B-cells. Biochem J 380:173-180

41. Gerard C, Rollins BJ 2001 Chemokines and disease. Nat Immunol 2:108-115

42. Luther SA, Cyster JG 2001 Chemokines as regulators of T cell differentiation. Nat Immunol 2:102-107

43. Mackay CR 2001 Chemokines: immunology's high impact factors. Nat Immunol 2:95-101

44. Heil M, Ziegelhoeffer T, Wagner S, Fernandez B, Helisch A, Martin S, Tribulova S, Kuziel WA, Bachmann G, Schaper W 2004 Collateral artery growth (arteriogenesis) after experimental arterial occlusion is impaired in mice lacking CC-chemokine receptor-2. Circ Res 94:671-677

45. Barlic J, Sechler JM, Murphy PM 2003 IL-15 and IL-2 oppositely regulate expression of the chemokine receptor CX3CR1. Blood 102:3494-3503

46. Kasper B, Brandt E, Bulfone-Paus S, Petersen F 2004 Platelet factor 4 (PF-4)-induced neutrophil adhesion is controlled by src-kinases, whereas PF-4-mediated exocytosis requires the additional activation of p38 MAP kinase and phosphatidylinositol 3-kinase. Blood 103:1602-1610

47. Schenk BI, Petersen F, Flad HD, Brandt E 2002 Platelet-derived chemokines CXC chemokine ligand (CXCL)7, connective tissue-activating peptide III, and CXCL4 differentially affect and cross-regulate neutrophil adhesion and transendothelial migration. J Immunol 169:2602-2610

48. Rose CE Jr, Sung SS, Fu SM 2003 Significant involvement of CCL2 (MCP-1) in inflammatory disorders of the lung. Microcirculation 10:273-288

49. Christen U, McGavern DB, Luster AD, von Herrath MG, Oldstone MB 2003 Among CXCR3 chemokines, IFN-gamma-inducible protein of $10 \mathrm{kDa}$ (CXC chemokine ligand (CXCL) 10) but not monokine induced by IFN-gamma (CXCL9) imprints a pattern for the subsequent development of autoimmune disease. J Immunol 171:6838-6845 